\title{
Depression, Anxiety and Stress among Health Care Professionals on Duty in COVID-19 Wards
}

\section{Authors}

1. Maham Noor Afroz

Jinnah Sindh Medical University

2. Syeda Maria Hassan

Jinnah Sindh Medical University

3. Kanwal Bansari

Jinnah Sindh Medical University

4. Humza Faisal Siddiqui

Jinnah Sindh Medical University

5. Sana Irfan

Jinnah Sindh Medical University

6. Basma Ali

Jinnah Sindh Medical University

7. Hamza Sohail

Jinnah Sindh Medical University

8. Zoha Batool

Jinnah Post Graduate Medical Center

9. Muhammad Khizar Memon

Liaquat University of Medical Health Sciences

10. Sidra Memon

Jinnah Post Graduate Medical Center

11. Faizan Shaukat; faizan.shaukat89@gmail.com

Jinnah Post Graduate Medical Center

Depression, Anxiety and Stress among Health Care Professionals on Duty in

COVID-19 Wards 


\begin{abstract}
Introduction: COVID-19 pandemic has affected HCPs in multiple way. It has caused psychological impact in form of anxiety, depression, and insomnia. In this study, we aim to study and compare the stress level, anxiety and depression among HCPs who are posted in special COVID-19 units with the HCPs who are not posted in COVID-19 units.

Methods: This cross-sectional study was conducted in June 2020, at various hospitals of Karachi, Pakistan. All health care professionals (HCPs) were invited to participate. A total of 301 HCPs completed this study, who were divided into two groups; those who are posted in COVID-19 ward (Group A) and those who are not (Group B). Psychological Impact was English version of the Depression Anxiety Stress Scale - 21 (DASS-21).

Results: In Group A, 70.5\% had moderate, severe, or extremely severe depression compared to $49.2 \%$ in group B. In Group A, 75.4\% had moderate, severe, or extremely severe anxiety compared to $44.7 \%$ in group B. In Group A, $80.3 \%$ had moderate, severe or extremely severe stress compared to $54.2 \%$ in group B. Anxiety, depression and stress were significantly higher in HCPs who were posted in COVID-19 ward compared to those who were not posted in COVID-19 ward

Conclusion: There was significantly higher anxiety, stress and depression in health care professionals posted in COVID-19 ward. Both the government and health care agencies should take responsibility for protecting the psychological well-being of health care communities all over the world and ensuring a healthy work environment.
\end{abstract}

Keyword: COVID-19, Depression, Anxiety, Stress, HCPs

\title{
Introduction
}

Coronavirus is an enveloped, single-stranded ribonucleic acid (RNA) virus that causes various respiratory diseases such as common cold, Severe Acute Respiratory Syndrome (SARS), and Middle East Respiratory Syndrome (MERS). COVID-19 (Corona Virus Disease - 19) first appeared in late 2019 in Wuhan, China. It is highly transmissible and was declared a pandemic in March 2020 by World Health Organization (WHO) [1]. Ever since the start of the pandemic, countries, and governments have been actively taking all measures to reduce the risk of virus transmission, including educating people about preventive measures. However, the most at-risk population is health care professionals (HCPs). There are various reasons why this pandemic has 
adversely affected HCPs, like long working hours, limited resources, and unreliable hospitals' unreliable infrastructure. Also, extensive protective measures that are needed by HCPs to protect themselves, such as wearing personal protective equipment (PPE) cause physical discomfort, breathing difficulties in HCPs [3], and facial scar marks [3].

Kang L and his colleagues studied the impact of a pandemic on the mental health of 994 medical and nursing staff of Wuhan, stating that around 6.2\% had severe disturbances, $22.4 \%$ had moderate disturbances, $34.4 \%$ had mild mental health disturbances, and 36.9\% had sub-threshold mental disturbances [4]. According to research in Pakistan conducted in July, Sandesh R and his colleagues concluded that HCPs suffered from moderate to severe stress levels $(90.1 \%)$, moderate to severe anxiety $(85.7 \%)$, and moderate to severe depression $(72.3 \%)$ [5]. However, this study had a single group, and there was no comparison with HCPs who did not work in the COVID-19 ward.

Hence, we aim to study and compare the stress level, anxiety, and depression among HCPs who are posted in COVID-19 units with the HCPs who are not posted in COVID-19 units. Through this study, we intend to highlight the emerging psychological issues of HCPs during this pandemic, which will serve as data for institutional and national bodies to plan interventions and policies to maintain the psychological health of HCPs.

\section{Methods and Materials}

This cross-sectional study was conducted in June 2020, at various hospitals in Pakistan. All health care professionals (HCPs) were invited to participate. A total of 301 HCPs completed this study, who were divided into two groups; those who are posted in the COVID-19 ward (Group A) and those who are not (Group B). Psychological Impact was measured using an English version of the Depression Anxiety Stress Scale - 21 (DASS-21). DASS-21 is a 21-item self-report validated tool designed to measure the three related negative emotional states: depression, anxiety, and stress [06].

All subjects gave their informed consent for inclusion before they participated in the study. The study was conducted in accordance with the Declaration of Helsinki. IRB was obtained from Jinnah Post graduate medical center (IRB-ERC-92) 
The collected data were analyzed using SPSS Version 21.0 (IBM Corp, Armonk, NJ). Mean and standard deviation (SD) were calculated for anxiety, stress, and depression scores. The severity of stress, anxiety, and depression was reported using frequencies and percentages. Frequencies were compared using Chi-square. A p-value of less than 0.05 indicates that the difference in DASS-21 Score between the groups is significant enough to discard the null hypothesis.

\section{Results}

Out of the 301 Health Care Professionals (HCPs) who participated in this study, 101 (57.1\%) were posted in COVID-19 ward, and 199 (42.9\%) were not posted in COVID-19 ward. The overall mean score of anxiety was $19.21 \pm 9.1$, depression was $18.74 \pm 10.65$, and stress was $19.99 \pm 12.3$ for HCPs posted in COVID-19 ward (Group A). The overall mean score of anxiety was $17.91 \pm$ 8.7, depression was $17.21 \pm 9.22$, and stress was $18.73 \pm 11.7$ for HCPs not posted in COVID-19 ward (Group B).

In Group A, 70.5\% had moderate, severe or extremely severe depression compared to $49.2 \%$ in group B. In Group A, 75.4\% had moderate, severe or extremely severe anxiety compared to $44.7 \%$ in group B. In Group A, 80.3\% had moderate, severe or extremely severe stress compared to 54.2\% in group B. Anxiety, depression and stress were significantly higher in HCPs who were posted in COVID-19 ward compared to those who were not posted in COVID-19 ward (Table 1).

\begin{tabular}{|c|c|c|c|c|c|c|c|c|c|}
\hline \multirow[t]{2}{*}{ DASS-21 } & \multicolumn{3}{|c|}{ Depression } & \multicolumn{3}{|l|}{ Anxiety } & \multicolumn{3}{|l|}{ Stress } \\
\hline & $\begin{array}{l}\text { Group A } \\
(\mathrm{n}=102)\end{array}$ & $\begin{array}{l}\text { Group B } \\
(n=199)\end{array}$ & $\begin{array}{l}\mathrm{P} \\
\text { value }\end{array}$ & $\begin{array}{l}\text { Group A } \\
(\mathrm{n}=102)\end{array}$ & $\begin{array}{l}\text { Group B } \\
(\mathrm{n}=199)\end{array}$ & $P$ value & $\begin{array}{l}\text { Group A } \\
(n=102)\end{array}$ & $\begin{array}{l}\text { Group B } \\
(n=199)\end{array}$ & $\mathrm{P}$ value \\
\hline Normal & $\begin{array}{l}11 \\
(10.7 \%)\end{array}$ & $\begin{array}{l}40 \\
(20.1 \%)\end{array}$ & & $\begin{array}{l}09 \\
(8.8 \%)\end{array}$ & $\begin{array}{l}38 \\
(19.0 \%)\end{array}$ & & $\begin{array}{l}06 \\
(5.8 \%)\end{array}$ & $\begin{array}{l}30 \\
(15.0 \%)\end{array}$ & .00013 \\
\hline Mild & $\begin{array}{l}19 \\
(18.6 \%)\end{array}$ & $\begin{array}{l}61 \\
(30.6 \%)\end{array}$ & & $\begin{array}{l}16 \\
(15.6 \%)\end{array}$ & $\begin{array}{l}72 \\
(36.1 \%)\end{array}$ & .000018 & $\begin{array}{l}14 \\
(13.7 \%)\end{array}$ & $\begin{array}{l}61 \\
(30.6 \%)\end{array}$ & \\
\hline
\end{tabular}




\begin{tabular}{|c|c|c|c|c|c|c|c|}
\hline Moderate & $\begin{array}{l}16 \\
(15.6 \%)\end{array}$ & $\begin{array}{l}28 \\
(14.0 \%)\end{array}$ & 0.007 & $\begin{array}{l}20 \\
(19.6 \%)\end{array}$ & $\begin{array}{l}30 \\
(15.0 \%)\end{array}$ & $\begin{array}{l}25 \\
(24.5 \%)\end{array}$ & $\begin{array}{l}39 \\
(19.5 \%)\end{array}$ \\
\hline Severe & $\begin{array}{l}42 \\
(41.1 \%)\end{array}$ & $\begin{array}{l}49 \\
(24.6 \%)\end{array}$ & & $\begin{array}{l}42 \\
(41.1 \%)\end{array}$ & $\begin{array}{l}42 \\
(21.1 \%)\end{array}$ & $\begin{array}{l}44 \\
(43.1 \%)\end{array}$ & $\begin{array}{l}45 \\
(22.6 \%)\end{array}$ \\
\hline $\begin{array}{l}\text { Extremely } \\
\text { Severe }\end{array}$ & $\begin{array}{l}14 \\
(13.7 \%)\end{array}$ & $\begin{array}{l}21 \\
(10.5 \%)\end{array}$ & & $\begin{array}{l}15 \\
(14.7 \%)\end{array}$ & $\begin{array}{l}17 \\
(8.54 \%)\end{array}$ & $\begin{array}{l}13 \\
(12.7 \%)\end{array}$ & $\begin{array}{l}24 \\
(12.0 \%)\end{array}$ \\
\hline
\end{tabular}

\section{Discussion}

Health Care Physicians (HCPs) are at increased risk of medical and psychological problems due to the pandemic, causing significant stress, anxiety, and depression. Various factors may cause psychological distress such as the risk of getting infection themselves, passing the infection to their family, and lack control over circumstances [7]. The fact that COVID-19 is human-to-human transmissible [8] and is associated with high morbidity and mortality compared to other viral infections [9] may increase personal danger perception. Other factors, such as the shortage of PPEs, medicines for patients, and an increase in the number of cases, may lead to increased stress and anxiety among HCPs [10]. Healthcare professionals have portrayed as 'superheroes' during this pandemic, which may lead to an additional sense of responsibility and pressure [11]. These factors may create a feeling of vulnerability and helplessness, which contributes to psychological disturbance such as worry, stress, anxiety, depression, and bad mood overall [3].

According to our study, HCPs posted in the COVID-19 ward, 70.5\% reported mild to severe depression, 75.4\% HCPs complained of mild to severe anxiety, and 80.3\% HCPs reported mild to severe stress. A study by Sandesh et al. reported similar results. His study found out that among the HCPs included in his study, $72.3 \%$ of them reported depression, $85.7 \%$ reported anxiety, and 90.1\% HCPs suffered from varying degrees [5]. Their study also analyzed the reasons behind these emerging mental health issues among HCPs. According to them, factors such as worry of getting infected despite protective gear (80.3\%) and fear of transmitting the infection to their families $(89.2 \%)$ were among the significant factors of such deteriorating psychological health. In other 
reasons, 64.2\% HCPs also reported increased workload, 62.5\% reported lack of Personal Protective Equipment, 62.5\% reported lack of security, and 46.4\% HCPs reported lack of knowledge among the general population [5].

Various contributing factors can be responsible for the high prevalence of anxiety, depression, and stress among Pakistan's HCPs. These factors include lack of proper infrastructure for patient care, low awareness among the general population, and poor compliance towards safety measures [5]. $\mathrm{Li} \mathrm{Zi}$ reported that even after some time had passed after an epidemic, there is evidence that there are high levels of anxiety, depression, stress, and some HCPs might suffer from PTSD [12].

As indicated by this study and other colleagues' work, there is a a high number of HCPs who are suffering from mental health ill-effects caused by the COVID-19 pandemic. Government and other responsible agencies should ensure measures to protect the mental well-being of healthcare professionals involved [13]. The government should also make efforts to reduce rumours and misinformation during the pandemic [14]. Based on WHO recommendations [15], people should be advised to wear a mask to reduce the transmission to lessen the burden on hospitals.

\section{Conclusion:}

In this study, there was high prevalence of anxiety, depression and stress among HCPs treating COVID-19 patients compared to those who were not posted in COVID-19 ward. It is responsibility of both government and health care agencies to ensure measures are taken to protect the mental health of HCPs. Various reforms should be introduced to lessen the burden on HCPs during this pandemic.

\section{References}

1. World Health Organization. Novel coronavirus (2019-nCoV) situation reports. (2020). Accessed: $\quad$ August $\quad$ 10, 2020: https://www.who.int/docs/defaultsource/coronaviruse/situation-reports/20200607-covid-19-sitrep139.pdf?sfvrsn=79dc6d08_2 
2. Shigemura J, Ursano RJ, Morganstein JC, Kurosawa M, Benedek DM: Public responses to the novel 2019 coronavirus (2019-nCoV) in Japan: mental health consequences and target populations. Psychiatry Clin Neurosci. 2020, 74:281-282. 10.1111/pcn.12988

3. Huang JZ, Han MF, Luo TD, Ren AK, Zhou XP: Mental health survey of 230 medical staff in a tertiary infectious disease hospital for COVID-19. 2020, 38:192195. 10.3760/cma.j.cn121094-20200219-00063

4. Kang L, Ma S, Chen M, et al. Impact on mental health and perceptions of psychological care among medical and nursing staff in Wuhan during the 2019 novel coronavirus disease outbreak: A cross-sectional study. Brain Behav Immun. 2020;87:11-17. doi:10.1016/j.bbi.2020.03.028

5. Sandesh R, Shahid W, Dev K, et al. (July 02, 2020) Impact of COVID-19 on the Mental Health of Healthcare Professionals in Pakistan. Cureus 12(7): e8974. doi:10.7759/cureus.8974

6. Arab M, Rafiei H, Safarizadeh MH, Ahmadi JS, Safarizadeh MM: Stress, anxiety and depression among medical university students and its relationship with their level of happiness. IOSR-JNHS. 2016, 5:44-47. 10.9790/1959-05164447

7. Wong TW, Yau JK, Chan CL, et al. . The psychological impact of severe acute respiratory syndrome outbreak on healthcare workers in emergency departments and how they cope. Eur J Emerg Med. 2005;12(1):13-18. 10.1097/00063110-200502000-00005

8. Wang W, Tang J, Wei F. Updated understanding of the outbreak of 2019 novel coronavirus (2019-nCoV) in Wuhan, China. J Med Virol. 2020;92(4):441-447. doi:10.1002/jmv.25689

9. Chan-Yeung M: Severe acute respiratory syndrome (SARS) and healthcare workers. Int J Occup Environ Health. 2004, 10:421-427. 10.1179/oeh.2004.10.4.421

10. Associação de Medicina Intensiva Brasileira. Recomendações para o bem-estar emocional da equipe multidisciplinar durante a pandemia pelo Sars-Cov-2 [text in Portuguese]. (2020). Accessed: July 2, 2020: https://www.amib.org.br/fileadmin/user_upload/amib/2020/marco/18/corona_psico _amib_15h56_18032020.pdf. 
11. Li Z, Ge J, Yang M, Feng J, Qiao M, Jiang R, et al. Vicarious traumatisation in the general public, members, and non-members of medical teams aiding in COVID-19 control. Brain Behav Immun 2020;S0889-1591(20):30309-3. 10.1016/j.bbi.2020.03.007.

12. Rothe C, Schunk M, Sothmann P, et al. Transmission of 2019-nCoV infection from an asymptomatic contact in Germany. N Engl J Med. 2020. 10.1056/NEJMc2001468

13. Wang C, Pan R, Wan X, Tan Y, Xu L, Ho CS, et al. Immediate psychological responses and associated factors during the initial stage of the 2019 Coronavirus disease (COVID19) epidemic among the general population in China. Int J Environ Res Public Health 2020; 17:E1729.

14. Rubin G.J., Wessely S. The psychological effects of quarantining a city. BMJ Clin. Res. Ed. 2020;368:m313. doi: 10.1136/bmj.m313.

15. Organisation W.H. Novel Coronavirus (2019-nCoV) Advice for the Public: When and How to Use Masks. [(accessed on 30 August 2020)];2020 Available online: https://www.who.int/emergencies/diseases/novel-coronavirus-2019/advice-forpublic/when-and-how-to-use-masks. 